\title{
Bjerkandera carnegieae comb. nov. (Phanerochaetaceae, Polyporales), a wood-decay polypore of cactus
}

\author{
Gerardo Robledo ${ }^{1,2,3^{*}}$, Karen K. Nakasone ${ }^{4 *}$ \& Beatriz Ortiz-Santana ${ }^{4}$
}

\section{Article info}

Received: 4 Nov. 2021

Revision received: 10 Dec. 2021

Accepted: 11 Dec. 2021

Published: 31 Dec. 2021

Associate Editor

Marcin Piątek

\begin{abstract}
Poria carnegieae was described from Arizona growing on the woody ribs of the saguaro cactus, Carnegiea gigantea, and was transferred to Ceriporiopsis due to morphological evidence. Posterior phylogenetic studies showed a relationship of Poria carnegieae with Bjerkandera. New sequence data and morphologic evidence are presented to support the transfer of Ceriporiopsis carnegieae to Bjerkandera.
\end{abstract}

Key words: host specificity, phlebioid clade, phylogeny, taxonomy

\section{Introduction}

Poria carnegieae was described from Arizona growing on the woody ribs of the saguaro cactus, Carnegiea gigantea (Baxter 1941). Cultural characters, decay studies, and sexuality of the species were described and studied by Gilbertson and Canfield (1972) and Lindsey and Gilbertson (1977). Gilbertson and Canfield (1972: 1309) noted that the bipolar mating system and negative phenol oxidase reaction placed $P$. carnegieae with Bjerkandera adusta (syn. Polyporus adustus) based on Nobles' 1965 key pattern of wood-decay fungal cultures. Because of morphological features such as an effused basidiome, light-colored pores, monomitic hyphal system with thinwalled, clamped generative hyphae, lack of cystidia, and thin-walled basidiospores, $P$. carnegieae was transferred to Ceriporiopsis by Gilbertson and Ryvarden (1985). In a multigene phylogenetic study of the order Polyporales by Justo et al. (2017), C. carnegieae was recovered in a clade with two species of Bjerkandera in the Phanerochaetaceae. Subsequent phylogenetic studies confirmed and supported this relationship (Chen et al. 2018; Motato-Vásquez et al. 2020; Wang et al. 2021). Due to differences in morphological features of the basidiome, such as its resupinate and effused habit and uniform, light-colored

\footnotetext{
${ }^{1}$ Universidad Nacional de Córdoba, Facultad de Ciencias Agropecuarias, Bio $_{T E C} A^{3}$ - Centro de Biotecnología Aplicada al Agro y Alimentos, Félix Aldo Marrone 746 - Planta Baja CC509 - CP 5000, Ciudad Universitaria, Córdoba, Argentina

${ }^{2}$ CONICET, Consejo Nacional de Investigaciones Científicas y Técnicas

${ }^{3}$ Fundación Fungicosmos, www.fungicosmos.org, Córdoba, Argentina

${ }^{4}$ USDA Forest Service, Northern Research Station, Center for Forest Mycology Research, One Gifford Pinchot Drive, Madison, Wisconsin, 53726, USA

* Corresponding authors e-mail: gerardo.robledo@agro.unc.edu.ar, karen.nakasone@usda.gov
}

context lacking a dark brown zone or black line between the tube layer and subiculum, researchers refrained from transferring C. carnegieae to Bjerkandera pending more data (Motato-Vásquez et al. 2020; Wang et al. 2021).

The purpose of this study is to provide additional phylogenetic and morphological evidence to support the transfer of Poria carnegieae to Bjerkandera. We also review additional biological information relating to this taxon.

\section{Materials and methods}

Morphological study

Specimens from the Center for Forest Mycology Research (CFMR) fungarium were studied. For microscopic analysis, free-hand sections of basidiomes were mounted in $2 \%(\mathrm{w} / \mathrm{v})$ aqueous potassium hydroxide $(\mathrm{KOH})$ and $1 \%$ (w/v) aqueous phloxine or Melzer's reagent. Cyanophily of hyphal and basidiospore walls was observed in $1 \%$ (weight/volume) cotton blue in $60 \%(\mathrm{w} / \mathrm{v})$ lactic acid. Basidiospores were measured in $\mathrm{KOH}$ and phloxine mounts under oil immersion with at $100 \times$ magnification. Q values were calculated from average spore length divided by average spore width of at least 30 spores. Color codes and names follow Kornerup \& Wanscher (1978). Micrographs of basidiomes were taken with an Olympus DP27 camera attached on an Olympus BX43 compound microscope.

\section{DNA extraction, PCR amplification and sequencing}

DNA extraction and amplification were performed from cultures at CFMR following a standard CTAB protocol (Mercado \& Ortiz-Santana 2018). Sequencing was 
Table 1. Taxon sampling: voucher specimens/cultures and GenBank accession numbers. New sequences generated in this study are in boldface. $(\mathrm{T})=$ type specimen

\begin{tabular}{|c|c|c|c|c|c|}
\hline \multirow{2}{*}{$\begin{array}{l}\text { Species } \\
\text { voucher/cultures }\end{array}$} & \multicolumn{5}{|c|}{ GenBank accession numbers } \\
\hline & ITS & LSU & tefl- $\alpha$ & $r p b 1$ & $r p b 2$ \\
\hline \multicolumn{6}{|l|}{ Outgroup } \\
\hline \multicolumn{6}{|c|}{ Candelabrochaete africana } \\
\hline FP-102987-sp & KP135294 & KP135199 & - & KP134872 & KP134975 \\
\hline \multicolumn{6}{|l|}{ Meruliaceae } \\
\hline \multicolumn{6}{|c|}{ Ceriporiopsis gilvescens } \\
\hline Niemela-5516 & HQ659222 & HQ659222 & - & - & - \\
\hline BRNM 710166 & FJ496684 & FJ496720 & - & - & - \\
\hline L3522sp & KY948760 & - & - & KY948919 & - \\
\hline \multicolumn{6}{|c|}{ Climacodon septentrionalis } \\
\hline AFTOL-767 & AY854082 & AY684165 & AY885151 & AY864872 & AY780941 \\
\hline \multicolumn{6}{|c|}{ Hydnophlebia chrysorhiza } \\
\hline FD-282 & KP135338 & KP135217 & - & KP134848 & KP134897 \\
\hline \multicolumn{6}{|l|}{ Mycoacia fuscoatra } \\
\hline HHB-10782-Sp & KP135365 & KP135265 & - & KP134857 & KP134910 \\
\hline \multicolumn{6}{|l|}{ Phlebia radiata } \\
\hline AFTOL-484 & AY 854087 & AF287885 & AY885156 & AY864881 & AY218502 \\
\hline \multicolumn{6}{|l|}{ Irpicaceae } \\
\hline \multicolumn{6}{|l|}{ Byssomerulius corium } \\
\hline FP-102382 & KP135007 & KP135230 & - & KP134802 & KP134921 \\
\hline \multicolumn{6}{|l|}{ Ceriporia reticulata } \\
\hline RLG-11354-Sp & KP135041 & KP135204 & - & KP134794 & KP134922 \\
\hline \multicolumn{6}{|l|}{ Efibula americana } \\
\hline FP-102165 & KP135016 & KP135256 & - & KP134808 & KP134916 \\
\hline \multicolumn{6}{|l|}{ Emmia lacerata } \\
\hline FP-55521-T & KP135024 & KP135202 & - & KP134805 & KP134915 \\
\hline \multicolumn{6}{|l|}{ Flavodon flavus } \\
\hline WHC 1381 & LC427029 & LC427052 & - & LC427064 & - \\
\hline \multicolumn{6}{|l|}{ Gloeoporus dichrous } \\
\hline BRNU 631507 & MG572751 & MG572735 & - & - & MG593280 \\
\hline FP-151129 & KP135058 & KP135213 & - & KP134866 & - \\
\hline \multicolumn{6}{|c|}{ Gloeoporus pannocinctus } \\
\hline L-15726-Sp & KP135060 & KP135214 & - & KP134867 & KP134973 \\
\hline Gloeoporus thelephor & & & & & \\
\hline BZ-289 & MG572757 & MG572741 & - & - & MG593286 \\
\hline Hydnopolyporus fimb & & & & & \\
\hline Meijer3729 (O) & JN649346 & JN649346 & JX109904 & - & JX109875 \\
\hline Irpex lacteus & & & & & \\
\hline FD-9 & KP135026 & KP135224 & - & KP134806 & - \\
\hline Meruliopsis cystidiato & & & & & \\
\hline 776308 & MG572749 & MG572733 & - & - & MG593278 \\
\hline Meruliopsis taxicola & & & & & \\
\hline SK 0075 (GB) & JX109847 & JX109847 & JX109901 & - & JX109873 \\
\hline Trametopsis cervina & & & & & \\
\hline TJV $93216 \mathrm{~T}$ & JN165020 & JN164796 & JN164882 & JN164839 & JN164877 \\
\hline Phanerochaetaceae & & & & & \\
\hline Bjerkandera adusta & & & & & \\
\hline Dai 14516 & MW507097 & MW520204 & - & - & - \\
\hline Dai 15665 & MW507098 & MW520205 & - & - & - \\
\hline Dai 15495 & MW507099 & - & - & - & - \\
\hline Dai 13201 & MW507100 & MW520206 & - & - & - \\
\hline Dai 12640 & MW507101 & - & - & - & - \\
\hline SFC20120409-08 & KJ704814 & KJ704829 & - & - & - \\
\hline SFC20111029-15 & KJ704813 & KJ704828 & - & - & - \\
\hline BRNM 771948 & КT305935 & KT305935 & KT305938 & - & - \\
\hline
\end{tabular}


Table 1. Continued.

\begin{tabular}{|c|c|c|c|c|c|}
\hline \multirow{2}{*}{$\begin{array}{l}\text { Species } \\
\text { voucher/cultures }\end{array}$} & \multicolumn{5}{|c|}{ GenBank accession numbers } \\
\hline & ITS & LSU & tefl- $\alpha$ & $r p b 1$ & $r p b 2$ \\
\hline HHB-12826-Sp & KP134983 & KP135198 & - & KP134784 & KP134913 \\
\hline HMCC-23 & MK051123 & - & MK051163 & MK051161 & MK051162 \\
\hline \multicolumn{6}{|l|}{ Bjerkandera albocinerea } \\
\hline MV $346(\mathrm{~T})$ & MH025421 & MH025421 & - & - & - \\
\hline RP 317 & MH025420 & - & - & - & - \\
\hline MW559 & МH025419 & МH025419 & - & - & - \\
\hline Dai 16411 & MW507102 & MW520207 & - & - & - \\
\hline \multicolumn{6}{|l|}{ Bjerkandera atroalba } \\
\hline SP 446205, MW 425 (T) & KT305930 & КT305930 & - & - & - \\
\hline SP 445629, MV 158 & KT305932 & KT305932 & KT305940 & - & - \\
\hline SP 445672, MV 266 & KT305931 & KT305931 & KT305939 & - & - \\
\hline Dai 17457 & MW507103 & MW520208 & - & - & - \\
\hline \multicolumn{6}{|l|}{ Bjerkandera carnegieae } \\
\hline ERC-71-366 & OL376625 & OL376623 & OL405698 & - & OL405701 \\
\hline RLG 10553 & OL376626 & OL376624 & - & - & - \\
\hline RLG-7277-T & KY948792 & KY948854 & OL405699 & KY948935 & OL405700 \\
\hline JV1209/45 & KX081134 & - & - & - & - \\
\hline JV0407/27-J & MW507122 & - & - & - & - \\
\hline \multicolumn{6}{|l|}{ Bjerkandera centroamericana } \\
\hline JK0610/A13 & KT305934 & KT305934 & KT305942 & - & - \\
\hline JK0610/A7 (T) & KT305933 & KT305933 & КT305941 & - & - \\
\hline JV1704/97 & MW507104 & - & - & - & - \\
\hline \multicolumn{6}{|l|}{ Bjerkandera ecuadoriensis } \\
\hline JV1906/C16-J (T) & MW507105 & - & - & - & - \\
\hline \multicolumn{6}{|l|}{ Bjerkandera fulgida } \\
\hline Dai $16107(\mathrm{~T})$ & MW507106 & MW520209 & - & - & - \\
\hline Dai 12284 & MW507107 & - & - & - & - \\
\hline Dai 13597 & MW507108 & MW520210 & - & - & - \\
\hline \multicolumn{6}{|l|}{ Bjerkandera fumosa } \\
\hline SFC20121009-04 & KJ704824 & KJ704839 & - & - & - \\
\hline BRNM771947 & KT305937 & KT305937 & - & - & - \\
\hline DAOM215869 & DQ060097 & AF287848 & - & - & - \\
\hline Dai 21100 & MW507109 & MW520211 & - & - & - \\
\hline Cui 10747 & MW507111 & MW520212 & - & - & - \\
\hline Dai 12674B & MW507112 & MW520213 & - & - & - \\
\hline Homble 1900 & KF698740 & KF698751 & - & - & - \\
\hline \multicolumn{6}{|l|}{ Bjerkandera mikrofumosa } \\
\hline MV 353 & MH025416 & MH025416 & - & - & - \\
\hline MV 363 & MH023526 & MH023526 & - & - & - \\
\hline MV 398 & MH023527 & MH023527 & - & - & - \\
\hline MV 420 & MH023525 & MH023525 & - & - & - \\
\hline MV 433 & MH025418 & - & - & - & - \\
\hline MV 435 & MH025417 & MH025417 & - & - & - \\
\hline Catania 3269 & MH025414 & - & - & - & - \\
\hline Robledo 1170 & MH025415 & - & - & - & - \\
\hline JV1707/10J-1 & MW507113 & - & - & - & - \\
\hline JV1707/10J-2 & MW507114 & - & - & - & - \\
\hline \multicolumn{6}{|l|}{ Bjerkandera minispora } \\
\hline Dai $15234(\mathrm{~T})$ & MW507115 & MW520214 & - & - & - \\
\hline Cui 5376 & MW507116 & MW520215 & - & - & - \\
\hline \multicolumn{6}{|l|}{ Bjerkandera resupinata } \\
\hline Dai $16642(\mathrm{~T})$ & MW507117 & MW520216 & - & - & - \\
\hline Cui 8017 & KU509526 & - & - & - & - \\
\hline \multicolumn{6}{|l|}{ Bjerkandera sp. } \\
\hline JV1512/13-J & MW507118 & - & - & - & - \\
\hline L13104sp & KY948791 & KY948855 & - & KY948936 & - \\
\hline
\end{tabular}


Table 1. Continued.

\begin{tabular}{|c|c|c|c|c|c|}
\hline \multirow{2}{*}{$\begin{array}{l}\text { Species } \\
\text { voucher/cultures }\end{array}$} & \multicolumn{5}{|c|}{ GenBank accession numbers } \\
\hline & ITS & LSU & tefl- $\alpha$ & $r p b 1$ & $r p b 2$ \\
\hline \multicolumn{6}{|l|}{ Donkia pulcherrima } \\
\hline GC 1707-11 & LC378994 & LC379152 & LC387371 & LC379157 & LC387351 \\
\hline \multicolumn{6}{|l|}{ Geliporus exilisporus } \\
\hline GC 1702-15 & LC378995 & LC379153 & LC387372 & LC379158 & LC387352 \\
\hline \multicolumn{6}{|l|}{ Hyphodermella rosae } \\
\hline FP-150552 & KP134978 & KP135223 & - & KP134823 & KP134939 \\
\hline \multicolumn{6}{|c|}{ Odontoefibula orientalis } \\
\hline Wu 0805-59 & LC363488 & LC363493 & LC387380 & LC363499 & LC387361 \\
\hline Wu 0910-57 & LC363490 & LC363495 & LC387381 & LC363501 & LC387362 \\
\hline \multicolumn{6}{|l|}{ Phanerina mellea } \\
\hline WEI 17-224 & LC387333 & LC387340 & LC387382 & LC387345 & LC387363 \\
\hline \multicolumn{6}{|c|}{ Phanerochaete chrysosporium } \\
\hline AFTOL-ID 776 & AY854086 & GQ470643 & AY885155 & AY864880 & - \\
\hline \multicolumn{6}{|l|}{ Phanerochaete sordida } \\
\hline Wu 0711-81 & LC387334 & MF110289 & LC270920 & LC387346 & LC387364 \\
\hline \multicolumn{6}{|c|}{ Phanerochaete taiwaniana } \\
\hline Wu 0112-13 & MF399412 & MF399403 & LC387383 & LC314332 & LC387365 \\
\hline \multicolumn{6}{|l|}{ Porostereum fulvum } \\
\hline LY 18491 & MG649452 & MG649454 & - & - & - \\
\hline LY 18496 & MG649453 & MG649455 & - & - & - \\
\hline \multicolumn{6}{|l|}{ Porostereum spadiceum } \\
\hline KUC 2013051 & KJ668473 & KJ668325 & - & - & - \\
\hline KUC20100728-24 & JX463661 & JX463655 & - & - & - \\
\hline KUC20080728-31 & JX463660 & JX463654 & - & - & - \\
\hline \multicolumn{6}{|l|}{ Rhizochaete radicata } \\
\hline FD-123 & KP135407 & KP135279 & - & KP134816 & KP134937 \\
\hline \multicolumn{6}{|l|}{ Rhizochaete rubescens } \\
\hline Wu 0910-45 & LC387335 & MF110294 & LC270925 & LC387348 & LC387370 \\
\hline \multicolumn{6}{|l|}{ Terana caerulea } \\
\hline FP 10473 & KP134980 & KP135276 & - & KP134865 & KP134960 \\
\hline
\end{tabular}

conducted at the University of Wisconsin Biotechnology Center (UWBC) in Madison, WI. The internal transcribed spacer region (ITS), including ITS1, 5.8S and ITS2, was amplified with primer pair ITS1F/ITS4 (Gardes \& Bruns 1993; White et al. 1990). The 5' end of the 28S large subunit of the nuclear ribosomal RNA (LSU) was amplified with primers LR0R (Cubeta et al. 1991) and LR5 (Vilgalys \& Hester 1990); tefl- $\alpha$ was amplified with primer pair EF1-983/EF1-1567R (Rehner \& Buckley 2005) and $r p b 2$ with primers bRPB2-6F and bRPB2-7.1R (Matheny 2005). Thermocycler conditions followed Kuo and Ortiz-Santana (2020). Newly generated sequences were edited with Sequencher 4.8 (Gene Codes Corp., Ann Arbor, Michigan).

\section{Phylogenetics analyses}

New DNA sequences generated in the present work were combined with sequences retrieved from GenBank (NCBI) to construct two datasets. Scientific names and GenBank Accession Numbers of sequences are listed in Table 1. Dataset 1 was composed of ITS, LSU, rpb1, rpb2 and tefl- $\alpha$ sequences of four Bjerkandera species with at least one coding marker and 31 species of the 'phlebioid clade' with representatives from the Phanerochaetaceae, Irpicaceae and Meruliaceae (Binder et al. 2013; Justo et al. 2017; Chen et al. 2018, 2020). Candelabrochaete africana was selected as outgroup (Justo et al. 2017; Chen et al. 2018). Dataset 2 was composed of ITS and LSU sequences of 13 Bjerkandera species with Porostereum (P. spadiceum and P. fulvum) as outgroup taxa (Motato-Vásquez et al. 2020; Wang et al. 2021).

ITS region was aligned using ProbCons 1.12 (Do et al. 2005), whereas LSU, $r p b 1, r p b 2$ and tefl- $\alpha$ were individually aligned using MAFFT 7 (Katoh et al. 2017) using the G-INS-i alignment method. Alignments were manually inspected and adjusted using MEGA 6 (Tamura et al. 2013). ModelFinder (Kalyaanamoorthy et al. 2017) as implemented in the IQ-Tree software (Nguyen et al. 2015) was used to estimate the best-fit partitioning strategy and the best-fit model of nucleotide evolution for the dataset using 16 data blocks (ITS1; 5.8S; ITS2; LSU; rpb1 codon positions, 1stpos, 2ndpos, and 3rdpos; rpb1 introns; rpb2 codon positions, 1stpos, 2ndpos, and 3rdpos; rpb2 introns; tefl- $\alpha$ codon positions 1 stpos, 2 ndpos, and 3 rdpos and tef1- $\alpha$ introns). Models were restricted for those implemented in MrBayes 3.2 (Ronquist et al. 2012). Bayesian inference (BI) and maximum likelihood (ML) phylogenetic analyses were applied to the concatenated datasets using the partition scheme and evolutionary models defined by ModelFinder. BI was performed following Robledo et al. (2020) in the CIPRES science gateway (Miller et al. 2010; http://www.phylo.org/). Maximum 
likelihood searches were conducted with IQ-TREE. The analyses initially involved $100 \mathrm{ML}$ searches, each one starting from one randomized stepwise addition parsimony tree. Branch supports were calculated using the UFBoot (ultrafast bootstrap approximation) (Hoang et al. 2018) implemented in IQ-TREE with 1000 replications. A node was considered strongly supported with BPP $\geq$ 0.95 or $\mathrm{BS} \geq 95 \%$ (Hyde et al. 2013; Minh et al. 2020).

\section{Results}

\section{Phylogenetic analyses}

Dataset 1 included 50 terminals and 6143 characters, of which 1990 were parsimony informative, 2527 were variable and 3213 constants. The partitions and evolutionary models selected were: GTR $+\mathrm{F}+\mathrm{I}+\mathrm{G} 4$ (ITS1, ITS2, rpb1 3rdpos), JC+I+G4 (5.8S), $\mathrm{K} 2 \mathrm{P}+\mathrm{I}+\mathrm{G} 4$ (LSU, tef1- $\alpha$ 1 stpos, tefl- $\alpha$ 2ndpos and rpb1 2ndpos), GTR $+\mathrm{F}+\mathrm{G} 4$ (tefl- $\alpha$ 3rdpos, rpb1 1stpos), HKY +F+I+G4 (tef1- $\alpha$ introns, $r p b 2$ introns, $r p b 2$ 1stpos), $\mathrm{SYM}+\mathrm{I}+\mathrm{G} 4$ ( $r p b 1$ introns, $r p b 2$ 2ndpos and $r p b 2$ 3rdpos). Bayesian and ML analyses resulted in identical topologies. The ML tree is presented in Figure 1. The topology showed 3 main lineages at family level recovered with maximum support: Phanerochaetaceae, Irpicaceae and Meruliaceae. This is congruent with previous works (Justo et al. 2017; Chen et al. 2018). Within Phanerochaetaceae, Bjerkandera conform a lineage with maximum support including $B$. adusta, type species of the genus, and $C$. carnegieae like previous works (Justo et al. 2017; Chen et al. 2018). These multi-loci phylogenetic analyses support the taxonomic position of $C$. carnegieae within Bjerkandera.

Dataset 2 included 58 terminals and 1988 characters, of which 155 were parsimony informative, 197 variable and 1787 constants. The partitions and evolutionary models selected were: $\mathrm{K} 2 \mathrm{P}+\mathrm{G} 4$ (ITS1 and ITS2), K2P+I (5.8S and LSU). Bayesian and ML analyses resulted in similar topologies. The ML tree is presented in Figure 2. In this ITS-LSU tree, $C$. carnegieae is in a basal position within Bjerkandera and consistent with previous work (Motato-Vásquez et al. 2020; Wang et al. 2021).

\section{Taxonomy}

Based on strong phylogenetic evidence presented above and new morphological observations presented below, we propose the transfer of Poria carnegieae to Bjerkandera. This transfer implies a slight modification of Bjerkandera concept, now including species with resupinate effused and adnate basidiomes and with a uniform context without a dark line or dark zone separating the tube layer from the context.

Bjerkandera carnegieae (D. V. Baxter) Robledo, Nakasone \& B. Ortiz, comb. nov.

(Fig. 3A-F)

MycoBank MB 841466

Basionym: Poria carnegieae D. V. Baxter, Papers of the Michigan Academy of Sciences 26: 110. 1941.

$\equiv$ Ceriporiopsis carnegieae (D. V. Baxter) Gilb. \& Ryvarden, Mycotaxon 22 (2): 364, 1985.
Descriptions and illustrations. Baxter (1941), Lowe (1966: 82), Gilbertson and Canfield (1972, basidiome and culture), Lindsey \& Gilbertson (1977, culture), Gilbertson and Ryvarden (1986: 189-190). Photograph of the specimen JV1209/45 (GenBank accession number KX081134) included in the phylogeny (Fig. 2) is available at the Polypore Collection of Dr. Josef Vlasák, Hluboká nad Vltavou, Czech Republic, Edition 18.II. 2015, http://mykoweb.prf. jcu.cz/polypores/index.html accessed October 28, 2021.

Remarks. Descriptions and illustrations of the basidiome are readily available (see above), and our observations generally agree except as follows: (1) The subicular trama is composed primarily of slightly thick- to thick-walled subicular hyphae 3-5.5 $\mu \mathrm{m}$ diam with walls thin to $1.5 \mu \mathrm{m}$ thick. (2) The tramal hyphae are 3-3.5 $\mu \mathrm{m}$ diam with walls thin to $0.5 \mu \mathrm{m}$ thick. (3) Basidia are clavate, $15-21 \times$ 5-5.5 $\mu \mathrm{m}$. (4) Basidiospores are slightly wider than previously reported, (4.5-)4.7-5.8 $\times(2.7-) 2.8-3 \mu \mathrm{m}, \mathrm{Q}=1.6-2$, average of 33 spores $=5.3 \pm 0.4 \times 3 \pm 0.2 \mu \mathrm{m}, \mathrm{Q}=1.8$.

Basidiomes of $B$. carnegieae are entirely effused and adnate with nearly white to ivory-white pores when fresh that darken slightly to light brown or buff, and a uniform, cream-colored context. The pore layer is very fragile and brittle when dried. These characters differ from most species of Bjerkandera which are pileate, effuse-reflexed, except the resupinate species $B$. resupinata. In addition, most species in the genus have dark gray to buff-colored pores that typically darken to black when bruised in contrast to the light-colored pores in $B$. carnegieae that darken to light brown. Furthermore, the context in $B$. carnegieae is uniformly light-colored, whereas other species of Bjerkandera have a tan, brown or black zone or line between the base of the tubes or pores and context. Motato-Vásquez et al. (2020) and Wang et al. (2021) have summarized some critical morphological characters of accepted species in Bjerkandera and included keys.

Despite these macromorphological differences with other species in the genus, $B$. carnegieae shares important characters such as a monomitic, clamped hyphal system of thin- to thick-walled generative hyphae with thick-walled hyphae dominating in the subiculum and trama (Fig. 3C-D), and basidia and basidiospores that are similar in shape and size. Furthermore, cultures of B. carnegieae, B. adusta, and $B$. fumosa share some important biological features, such as developing arthroconidia and a negative or weakly positive reaction on gallic acid agar with some mycelial growth and a negative or positive reaction on tannic acid agar, but no growth (Nobles 1948: 350; Gilbertson \& Canfield 1972; Lombard et al. 1992). Finally, these three species have a heterocytic nuclear behavior and a bipolar mating system (Gilbertson \& Canfield 1972; David 1988; Lombard et al. 1992). It is noteworthy that cultures of B. mikrofumosa and $B$. atroalba develop chlamydospores and not arthroconidia (Motato-Vásquez et. al. 2016, 2020).

Specimens examined. (All on saguaro, Carnegiea gigantea at CFMR): U.S.A., Arizona. Pinal County, Santa Rosa Valley, Papago Indian Reservation, Gu Komelik, 11 November 1971, E. R. Canfield, ERC 71-366 and ERC 71-367; Chiu Chiuschu, 11 November 1971, R. L. Gilbertson, RLG 10553. Pima County, 


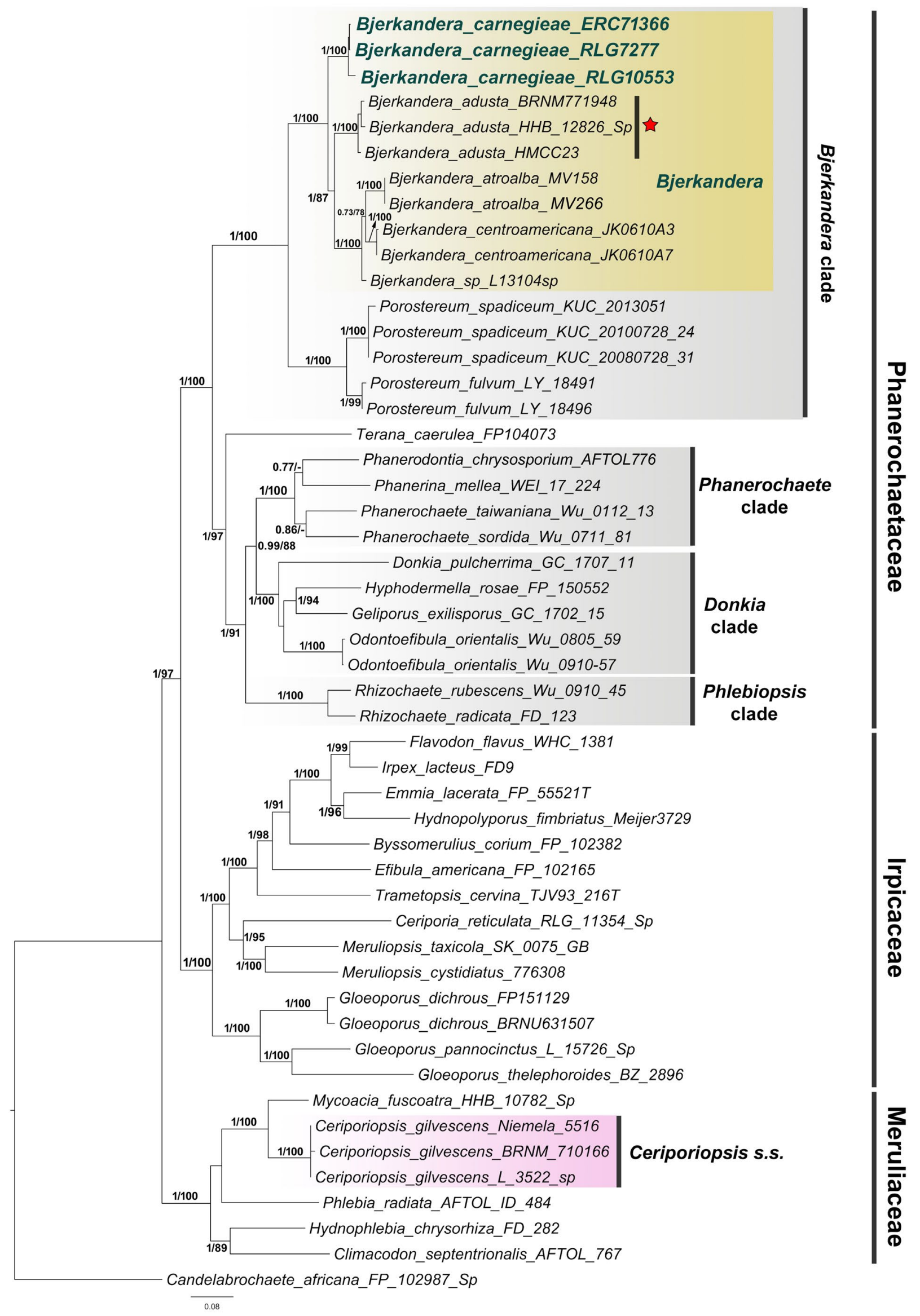

Figure 1. Maximum Likelihood (ML) tree of Phanerochaetaceae based on concatenated dataset of ITS + LSU $+r p b 1+r p b 2+t e f 1-\alpha$ sequence data. Branch support values are shown as BPP/BS, Bayesian posterior probability above 0.7 and Bootstrap values above $70 \%$. $\star=$ type species of Bjerkandera. 


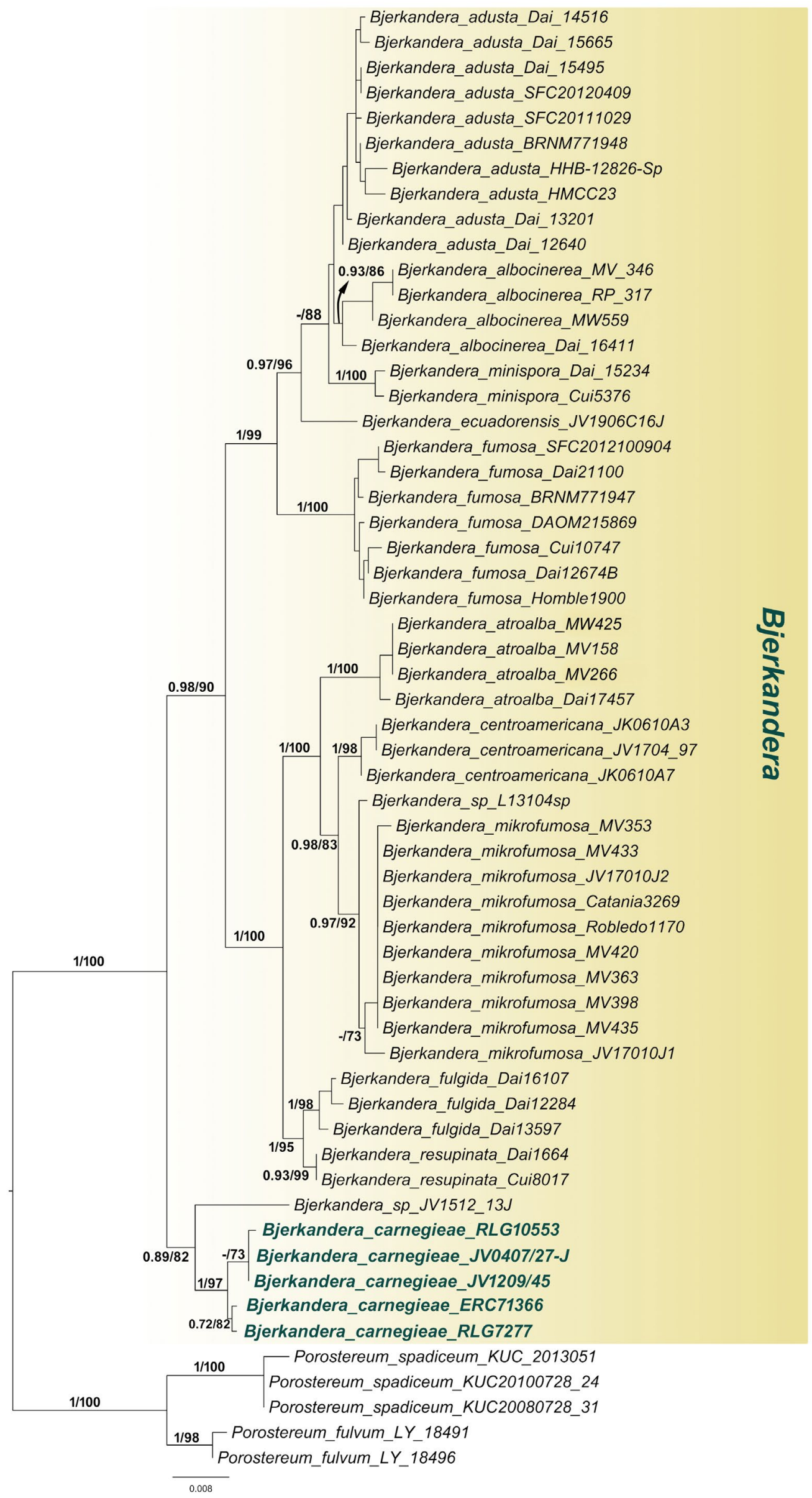

Figure 2. Maximum Likelihood (ML) tree of Bjerkandera based on concatenated dataset of ITS + LSU sequence data. Branch support values are shown as BPP/BS, Bayesian posterior probability above 0.7 and Bootstrap values above $70 \%$. 

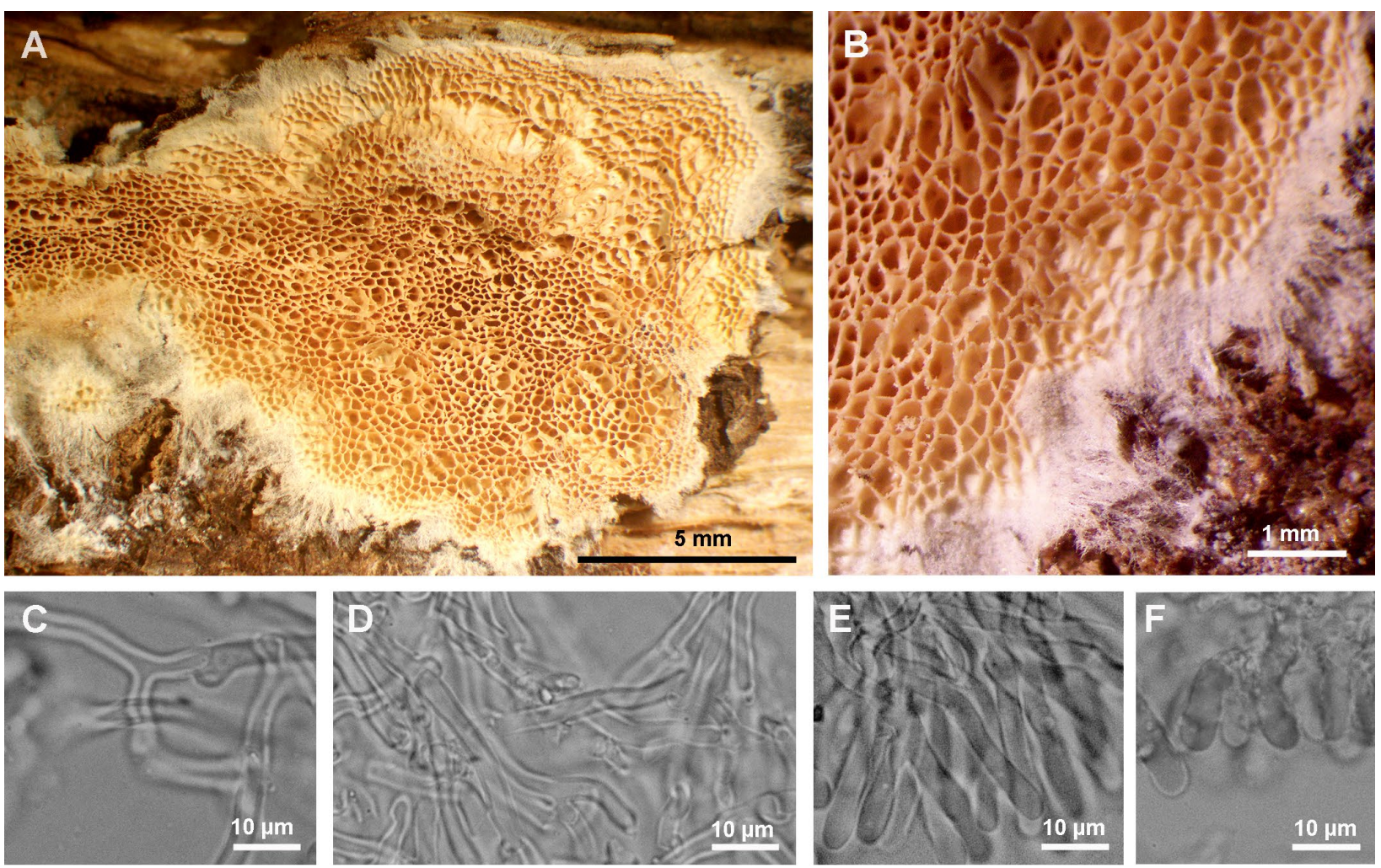

Figure 3. Morphological features Bjerkandera carnegieae (specimen ERC71366) A-B, macromorphological features: A - general view of basidioma; B - detail of pores and margin. C-E - microscopic features: C - contex; D - trama of the tubes; E - dissepiment edge; F - hymenium. Pictures by K. Nakasone.

Saguaro National Monument, 30 August 1967, R. L. Gilbertson, RLG-7277; near San Pedro Valley, Redington Road, 26 February 1971, R. L. Gilbertson, RLG 10081; Tucson Mountains, Picture Rocks Pass, 24 October 1972, J. P. Lindsey, JPL 93.

\section{Discussion}

Our multi-gene phylogenetic tree of the phlebioid clade shown in Figure 1 is consistent with previous studies (Justo et al. 2017; Chen et al. 2018). Similarly, the ITS-LSU analysis of the genus Bjerkandera recovered a tree shown in Figure 2 that is congruent with that in Motato-Vásquez et al. (2020) and Wang et al. (2021). Phylogenetic studies showed that the current concept of Ceriporiopsis is polyphyletic with species recovered in several different phylogenetic clades (Tomšovský et al. 2010; Zhao \& Cui 2014; Gómez-Montoya et al. 2017). The type of Ceriporiopsis, C. gilvescens, clusters in a lineage with Phlebia and Mycoacia (Binder et al. 2013; Zhao \& Cui 2014; Zhao \& Wu 2016; Justo et al. 2017).

The transfer of $P$. carnegieae to Bjerkandera requires a slight modification to the genus description to include species with effused basidiomes and uniform context without a dark line or dark zone separating the tube layer from the context. We believe that this is a better solution than the creation of a new genus for $B$. carnegieae that lacks strong phylogenetic, morphological, or biological characters. More studies of Bjerkandera sp. JV1512/13J (as Ceriporiopsis sp. in Wang et al. 2021) and Bjerkandera sp. L13104sp, both from Costa Rica, are required to see if sequence data are also supported by morphological and biological characters to describe it as a new taxon.
Bjerkandera carnegieae was originally described by Baxter (1941) from southern Arizona as an important agent of decay in the saguaro cactus, Carnegiea gigantea. Most specimens of this species are from saguaro, but a few specimens are also known on other woody $\mathrm{Cac}$ taceae, such as Pachycereus sp and Lemaireocereus sp, from desert areas of Mexico (Lindsey \& Gilbertson 1977; and data retrieved from MycoPortal, October 15, 2021). ITS BLAST searches in GenBank have recovered some environmental samples with $100 \%$ sequence identity with $B$. carnegieae, mostly from Arizona, but also from Puerto Rico and Brazil (Fröhlich-Nowoisky et al. 2012). Although the fungal diversity growing in saguaro has been recorded (Gilbertson et al. 1974; Lindsey \& Gilbertson 1975), tree-like cacti are 'under sampled' in other parts of America. The biographical connection of desert areas from USA and Central Argentina has been previously reported, not only in similar physiognomic structure, spiny bush and trees and tree-like cacti, but in plant taxa, i.e. Prosopis spp., and polypores are not the exception. See for instance Inocutis texana, originally described from North America that has been registered in xerophitic areas of central Argentina (Robledo \& Urcelay 2009; Rajchenberg $\&$ Robledo 2013). The only polypore so far registered in a tree-like cactus in Central Argentina has been Ceriporia xylostromatoides, growing inside a dead falling Stetsonia coryne (Robledo \& Urcelay 2009).

\section{Acknowledgements}

This work was supported by FONCYT (PICT 0830 to G. Robledo) and Fundación Fungicosmos. The authors would also 
like to acknowledge the Center for Forest Mycology Research (CFMR) for making available culture and collections for this study. The assistance of Consejo Nacional de Investigaciones Científic as y Técnicas (CONICET) and Universidad Nacional de Córdoba, both of which supported the facilities used in this work, is also acknowledged.

\section{References}

Baxter, D. W. 1941. Some resupinate polypores from the region of the Great Lakes. XII. Papers of the Michigan Academy of Science, Arts and Letters 26: 107-121.

Binder, M., Justo, A., Riley, R., Salamov, A., Lopez-Giraldez, F., Jökvist, E., Copeland, A., Foster, B., Sun, H., Larsson, E., Larsson, K. H., Townsend, J, Grigoriev, I. V. \& Hibbet, D. S. 2013. Phylogenetic and phylogenomic overview of the Polyporales. Mycologia 105: 1350-1373. https://doi.org/10.3852/13-003

Chen, C-C., Wu, S-H. \& Chen, C-Y. 2018. Hydnophanerochaete and Odontoefibula, two new genera of phanerochaetoid fungi (Polyporales, Basidiomycota) from East Asia. MycoKeys 39: 75-96. https:// doi.org/10.3897/mycokeys.39.28010

Chen, C-C., Chen, C-Y., Lim, Y. W. \& Wu, S-H. 2020. Phylogeny and taxonomy of Ceriporia and other related taxa and description of three new species. Mycologia 112: 64-82. https://doi.org/10.1080 /00275514.2019.1664097

Cubeta, M. A., Echandi, E., Abernethy, T. \& Vilgalys, R. 1991. Characterization of anastomosis groups of binucleate Rhizoctonia species using restriction analysis of an amplified ribosomal RNA gene. Molecular Plant and Pathology 81: 1395-1400.

David, A. 1988. Bedeutung des Studiums des Kernverhaltens in der Systematik der Polyporaceae. In: Wolkinger, F. (ed.), Internationales Aphyllophorales-Symposium Eisenstadt 1982, pp. 23-28. Graz: Austrian Academy of Sciences.

Do, C. B., Mahabhashyam, M. S., Brudno, M. \& Batzoglou, S. 2005. ProbCons: Probabilistic consistency-based multiple sequence alignment. Genome Resreach 15(2): 330-340. https://doi.org/10.1101/ gr. 2821705

Fröhlich-Nowoisky, J., Burrows, S. M., Xie, Z., Engling, G., Solomon, P. A., Fraser, M. P., Mayol-Bracero, O. L., Artaxo, P., Begerow, D., Conrad, R., Andreae, M. O., Després, V. R. \& Pöschl, U. 2012. Biogeography in the air: fungal diversity over land and oceans. Biogeosciences 9: 1125-1136. https://doi.org/10.5194/bg-9-1125-2012

Gardes, M. \& Bruns, T. D. 1993. ITS primers with enhanced specificity for basidiomycetes application to the identification of mycorrhizae and rusts. Molecular Ecology 2: 113-118. https://doi.org/10.1111/ j.1365-294x.1993.tb00005.x

Gilbertson, R. L. \& Canfield, E. R. 1972. Poria carnegiea and decay of Saguaro cactus in Arizona. Mycologia 64(6): 1300-1311. https:// doi.org/10.1080/00275514.1972.12019381

Gilbertson, R. L. \& Ryvarden, L. 1985. Some new combinations in the Polyporaceae. Mycotaxon 22: 363-365.

Gilbertson, R. L. \& Ryvarden, L. 1986. North American Polypores. Vol. I. Fungiflora. Oslo. Noruega.

Gilbertson, R. L., Martin, K. J. \& Lindsey, J. P. 1974. Annotated check list and host index for Arizona wood-rotting fungi. University of Arizona Agricultural Experiment Station Technical Bulletin 209: 1-48.

Gómez-Montoya, N., Drechsler-Santos, E. R., Ferreira Lopes, V., Tomšovský, M., Urcelay, C. \& Robledo, G. L. 2017. New insights on Trametopsis Tomšovský (Polyporales Gäum) based on phylogenetic evidences and morphological analyses of neotropical species. Phytotaxa 311(2): 155-167. https://doi.org/10.11646/phytotaxa.311.2.3

Hoang, D. T., Chernomor, O., von Haeseler, A., Minh, B. Q. \& Vinh, L. S. 2018. UFBoot2: Improving the ultrafast bootstrap approximation. Molecular Biology and Evolution 35: 518-522. https://doi. org/10.1093/molbev/msx281
Hyde, K. D., Udayanga, D., Manamgoda, D. S., Tedersoo, L., Larsson, E., Abarenkov, K., Bertrand, Y. J.K., Oxelman, B., Hartmann, M., Kauserud, H., Ryberg, M., Kristiansson, E. \& Nilsson, R. H. 2013. Incorporating molecular data in fungal systematics: a guide for aspiring researchers. Current Research in Environmental and Applied Mycology 3: 1-32.

Justo, A., Miettinen, O., Floudas, D., Ortiz-Santana, B., Sjökvist, E., Lindner, D., Nakasone, K., Niemelä, T., Larsson, K. H., Ryvarden, L. \& Hibbett, D. S. 2017. A revised family-level classification of the Polyporales (Basidiomycota). Fungal Biology 121: 798-824. https://doi.org/10.1016/j.funbio.2017.05.010

Kalyaanamoorthy, S., Minh, B., Wong, T., von Haeseler, A. \& Jermiin, L. S. 2017. ModelFinder: fast model selection for accurate phylogenetic estimates. Nature Methods 14: 587-589. https://doi. org/10.1038/nmeth.4285

Katoh, K., Rozewicki, J. \& Yamada, K. D. 2017. MAFFT online service: multiple sequence alignment, interactive sequence choice and visualization. Briefings in Bioinformatics 20: 1160-1166. https:// doi.org/10.1093/bib/bbx108

Kornerup, A. \& Wanscher, J. H. 1978. Methuen Handbook of Colour. London: Eyre Methuen.

Kuo, M. \& Ortiz-Santana, B. 2020. Revision of leccinoid fungi, with emphasis on North American taxa, based on molecular and morphological data. Mycologia 112(1): 197-211. https://doi.org/10.10 $80 / 00275514.2019 .1685351$

Lindsey, J. P. \& Gilbertson, R. L. 1977. Some aspects of bipolar heterothallism and other cultural characters of Poria carnegiea. Mycologia 69(4): 761-772.

Lindsey, J. P. \& Gilbertson, R. L. 1975. Wood-inhabiting Homobasidiomycetes on saguaro in Arizona. Mycotaxon 2: 83-103. https:// doi.org/10.1080/00275514.1977.12020121

Lombard, F. F., Larsen, M. J. \& Dorworth, E. B. 1992. Reassessment of the sexual incompatibility system and cultural characteristics of Bjerkandera fumosa. Mycologia 84(3): 406-410. https://doi.org/10 $.1080 / 00275514.1992 .12026154$

Lowe, J. L. 1966. Polyporaceae of North America. The genus Poria. Technical publications, New York State College of Forestry at Syracuse University No. 90: 1-183.

Matheny, P. B. 2005. Improving phylogenetic inference of mushrooms with RPB1 and RPB2 nucleotide sequences (Inocybe, Agaricales). Molecular Phylogenetics and Evolution 35: 1-20. https://doi. org/10.1016/j.ympev.2004.11.014

Mercado, E. M. \& Ortiz-Santana, B. 2018. Mountain pine beetle mutualist Leptographium longiclavatum presence in the southern Rocky Mountains during a record warm period. Sydowia 70: 1-10. https:// doi.org/10.12905/0380.sydowia70-2018-0001

Miller, M. A., Pfeiffer, W. \& Schwartz, T. 2010. Creating the CIPRES Science Gateway for inference of large phylogenetic trees. Gateway Computing Environments Workshop (GCE), IEEE: 1-8.

Minh, B. Q., Hahn, M. W. \& Lanfear, R. 2020. New methods to calculate concordance factors for phylogenomic datasets. Molecular Biology and Evolution 37: 2727-2733. https://doi.org/10.1093/ molbev/msaa106

Motato-Vásquez, V., Pires, R. M., Vitali, V. M. V. \& Gugliotta, A. M. 2016. Cultural and ligninolytic activity studies of some polypores (Basidiomycota) from Brazilian Atlantic Forest, São Paulo State, Brazil. Hoehnea 43(2): 289-300. https://doi.org/10.1590/22368906-81/2015

Motato-Vásquez, V., Gugliotta, A. M., Rajchenberg, M., Catania, M., Urcelay, C. \& Robledo, G. L. 2020. New insights on Bjerkandera (Phanerochaetaceae, Polyporales) in the Neotropics with description of Bjerkandera albocinerea based on morphological and molecular evidence. Plant Ecology and Evolution 153: 229-245. https://www.jstor.org/stable/26927027

Nobles, M. K. 1948. Studies in forest pathology. VI. Identification of cultures of wood-rotting fungi. Canadian Journal of Research, Section C 26: 281-431. 
Nguyen, L. T., Schmidt, H. A., von Haeseler, A. \& Minh, B. Q. 2015. IQ-TREE: A fast and effective stochastic algorithm for estimating maximum likelihood phylogenies. Molecular Biology and Evolution 32: 268-274. https://doi.org/10.1093/molbev/msu300

Rajchenberg, M. \& Robledo, G. 2013. Pathogenic polypores in Argentina. Forest Pathology 43(3): 171-184. https://doi.org/10.1111/ efp. 12032

Rehner, S. A. \& Buckley, E. 2005. A Beauveria phylogeny inferred from nuclear ITS and EF1- $\alpha$ sequences: evidence for cryptic diversification and links to Cordyceps teleomorphs. Mycologia 97: 84-98. https://doi.org/10.3852/mycologia.97.1.84

Robledo, G. L. \& Urcelay, C. 2009. Hongos de la madera en árboles nativos del centro de Argentina. Editorial Universitaria, Universidad Nacional de Córdoba. Córdoba, Argentina.

Robledo, G. L., Palacio, M., Urcelay, C., Vasco-Palacios, A. M., Crespo, E., Popoff, O., Põldmaa, K., Ryvarden, L. \& Costa-Rezende, D. H. 2020. Mystery unveiled: Diacanthodes Singer-a lineage within the core polyporoid clade. Systematics and Biodiversity 19: 725-741. https://doi.org/10.1080/14772000.2020.1776784

Ronquist, F., Teslenko, M., van der Mark, P., Ayres, D. L., Darling, A., Höhna, S. \& Huelsenbeck, J. P. 2012. MrBayes 3.2: efficient Bayesian phylogenetic inference and model choice across a large model space. Systematic Biology 61: 539-542. https://doi.org/10.1093/ sysbio/sys029

Tamura, K., Stecher, G., Peterson, D., Filipski, A. \& Kumar, S. 2013. MEGA6: Molecular Evolutionary Genetics Analysis Version 6.0. Molecular Biology and Evolution 30: 2725-2729. https://doi. org/10.1093/molbev/mst197
Tomšovský, M., Menkis, A. \& Vasaitis, R. 2010. Phylogenetic relationships in European Ceriporiopsis species inferred from nuclear and mitochondrial ribosomal DNA sequences. Fungal Biology 114: 350-358. https://doi.org/10.1016/j.funbio.2010.02.004

Vilgalys, R. \& Hester, M. 1990. Rapid genetic identification and mapping of enzymatically amplified ribosomal DNA from several Cryptococcus species. Journal of Bacteriology 172: 4238-4246. https:// doi.org/10.1128/jb.172.8.4238-4246.1990

Wang, C-G., Vlasák, J. \& Dai, Y-C. 2021. Phylogeny and diversity of Bjerkandera (Polyporales, Basidiomycota), including four new species from South America and Asia. MycoKeys 79: 149-172. https://doi.org/10.3897/mycokeys.79.63908

White, T. J., Bruns, T., Lee, S. S. \& Taylor, J. 1990. Amplification and direct sequencing of fungal ribosomal RNA genes for phylogenetics. In: Innis, M. A., Gelfand, D. H., Sninsky, J. J. \& White, T. J. (eds), PCR protocols: A guide to methods and applications, pp. 315-322. Academic Press, New York.

Zhao, C. L. \& Cui, B. K. 2014. Phylogeny and taxonomy of Ceriporiopsis (Polyporales) with descriptions of two new species from southern China. Phytotaxa 164: 17-28. https://doi.org/10.11646/ phytotaxa.164.1.2

Zhao, C. L. \& Wu, Z. Q. 2017. Ceriporiopsis kunmingensis sp. nov. (Polyporales, Basidiomycota) evidenced by morphological characters and phylogenetic analysis. Mycological Progress 16: 93-100. https://doi.org/10.1007/s11557-016-1259-8 